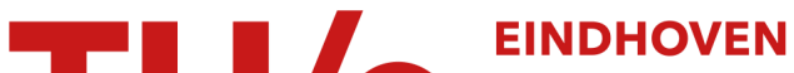 UNIVERSITY OF TECHNOLOGY
}

\section{Crystallization and dissolution of flow-induced precursors}

\section{Citation for published version (APA):}

Balzano, L., Kukalyekar, N. P., Rastogi, S., Peters, G. W. M., \& Chadwick, J. C. (2008). Crystallization and dissolution of flow-induced precursors. Physical Review Letters, 100(4), 048302-1/4. [048302].

https://doi.org/10.1103/PhysRevLett.100.048302

DOI:

10.1103/PhysRevLett.100.048302

Document status and date:

Published: 01/01/2008

\section{Document Version:}

Publisher's PDF, also known as Version of Record (includes final page, issue and volume numbers)

\section{Please check the document version of this publication:}

- A submitted manuscript is the version of the article upon submission and before peer-review. There can be important differences between the submitted version and the official published version of record. People interested in the research are advised to contact the author for the final version of the publication, or visit the $\mathrm{DOI}$ to the publisher's website.

- The final author version and the galley proof are versions of the publication after peer review.

- The final published version features the final layout of the paper including the volume, issue and page numbers.

Link to publication

\section{General rights}

Copyright and moral rights for the publications made accessible in the public portal are retained by the authors and/or other copyright owners and it is a condition of accessing publications that users recognise and abide by the legal requirements associated with these rights.

- Users may download and print one copy of any publication from the public portal for the purpose of private study or research.

- You may not further distribute the material or use it for any profit-making activity or commercial gain

- You may freely distribute the URL identifying the publication in the public portal.

If the publication is distributed under the terms of Article $25 \mathrm{fa}$ of the Dutch Copyright Act, indicated by the "Taverne" license above, please follow below link for the End User Agreement:

www.tue.nl/taverne

Take down policy

If you believe that this document breaches copyright please contact us at:

openaccess@tue.nl

providing details and we will investigate your claim. 


\title{
Crystallization and Dissolution of Flow-Induced Precursors
}

\author{
Luigi Balzano, ${ }^{1,4}$ Nileshkumar Kukalyekar, ${ }^{1,4}$ Sanjay Rastogi, ${ }^{1,3,4, *}$ Gerrit W. M. Peters, ${ }^{2,4}$ and John C. Chadwick ${ }^{1,4}$ \\ ${ }^{1}$ Department of Chemical Engineering, Eindhoven University of Technology, P.O. Box 513, 5600 MB, Eindhoven, The Netherlands \\ ${ }^{2}$ Department of Mechanical Engineering, Eindhoven University of Technology, P.O. Box 513, 5600 MB, Eindhoven, The Netherlands \\ ${ }^{3}$ Institute of Polymer Technology and Materials Engineering (IPTME), Loughborough University, \\ Loughborough, LE11 3TU, United Kingdom \\ ${ }^{4}$ Dutch Polymer Institute (DPI), P.O. Box 902, 5600 AX Eindhoven, The Netherlands
}

(Received 12 September 2007; published 1 February 2008)

\begin{abstract}
We make use of a specially synthesized linear high density polyethylene with a bimodal molecular weight distribution (MWD) to demonstrate that it is possible to produce a suspension of extended-chain (shish) crystals only. Such a suspension can be generated at high temperatures, above but close to the equilibrium melting temperature of the unconstrained extended-chain crystals $\left(T_{m}^{0}=141.2^{\circ} \mathrm{C}\right)$ and requires stretch of the longest chains of the MWD. After the application of a shear flow of $120 \mathrm{~s}^{-1}$ for $1 \mathrm{~s}$ at $142^{\circ} \mathrm{C}$, x-ray scattering suggests the presence of a large number of metastable needlelike precursors with limited or no crystallinity. Precursors that are too small dissolve on a timescale that correlates perfectly with the reptation time of the longest polymer molecules. Whereas, precursors that exceed a critical size crystallize forming extended-chain shishes.
\end{abstract}

Semicrystalline polyolefins are a widespread class of polymeric materials. In the most common scenarios, these materials are shaped into final products starting from the melt and processing involves the application of flows. Already in the 1960s, it was realized that the properties of the final products depend on the crystalline morphology of the material. Experiments prove that the final morphology is often imposed by structures (crystalline or not) present in the melt at the early stages of the crystallization. These structures are referred to as precursors and are problematic to study because of small dimensions and fast dynamics. However, improving techniques such as in situ small and wide angle X-ray scattering (SAXS and WAXS) and ex situ microscopy together with increasingly sophisticated simulations are contributing to a more thorough understanding of the physics behind the early stages of crystallization.

In this Letter, we discuss some peculiar aspects of the early stages of flow-induced crystallization (FIC). One of the seminal works for FIC is by Binsbergen [1]. He studied FIC in isotactic polypropylene by means of cross polarized optical microscopy. During cooling, after the application of "large strains" at $180^{\circ} \mathrm{C}$, he observed birefringent elongated crystallites at temperatures as high as $172^{\circ} \mathrm{C}$ where, in quiescent conditions, no crystallization is observed. Similar birefringence was also observed by Pennings in stirred polyethylene (PE) solutions [2]. This morphology, schematically reproduced in Fig. 1, was called shish kebab and originates from the crystallization of polymer chains stretched during flow. The structure of shish kebabs consists of an extended-chain crystal (ECC) core, shish, that supports disklike folded chain crystals (FCC), kebabs. The nature of shish kebabs in polyolefin melts and the conditions under which they form have been studied by several groups [3-15]. Keller and co-workers [16] hypothesized that, during flow, molecules can be coiled or stretched depending on their molar mass $M$. Molecules with $M$ above a critical value $M^{*}$ are stretched and instantaneously crystallize with an extended-chain structure, i.e., forming shishes. In contrast, molecules with $M<M^{*}$ cannot be stretched and relax immediately. These low-molar-mass chains nucleate folding on the outer surface of the shishes giving rise to the kebabs. Hypothesizing a critical $M^{*}$ for chain stretch in an entangled polymer melt has some limitations. In fact, in this model, all chains with $M>$ $M^{*}$ should stretch during flow, whereas molecular dynam-

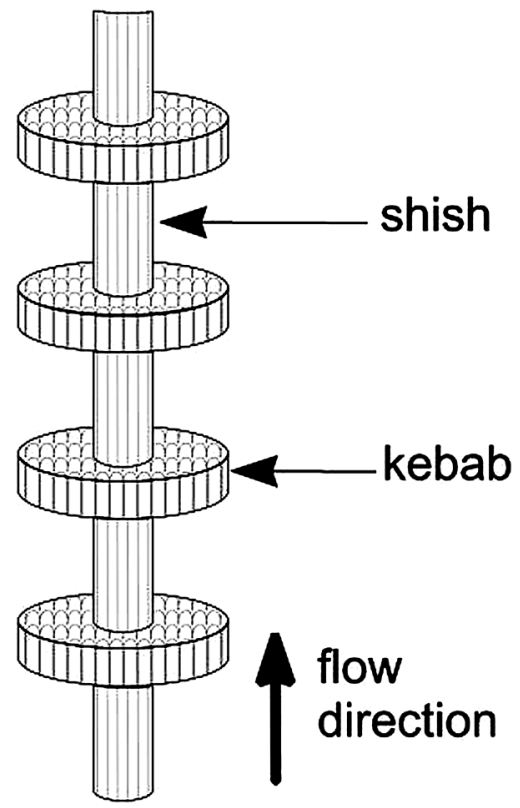

FIG. 1. Schematic drawing of a shish-kebab crystallite. 
TABLE I. Summary of the specification of the investigated bimodal HDPE blend. The number of entanglements $Z=M_{w} / M_{e}$ is calculated with $M_{e}=828 \mathrm{~g} / \mathrm{mol}$.

\begin{tabular}{lcclcccccc}
\hline \hline & \multicolumn{3}{c}{$\mathrm{GPC}$} & & & & \multicolumn{3}{c}{$\mathrm{DSC}\left(10^{\circ} \mathrm{C} / \mathrm{min}\right)$} \\
\hline $\mathrm{LMW}^{\mathrm{a}}$ & $\mathrm{LMW}$ & $Z_{\mathrm{LMW}}$ & $\mathrm{HMW}^{\mathrm{b}}$ & $\mathrm{HMW}$ & & $\mathrm{HMW}$ & $T_{m}$ & $T_{c}$ & Crystallinity at room \\
{$[\mathrm{g} / \mathrm{mol}]$} & $M_{w} / M_{n}$ & & {$[\mathrm{~g} / \mathrm{mol}]$} & $M_{w} / M_{n}$ & $Z_{\mathrm{HMW}}$ & {$[\mathrm{wt} \%]$} & {$\left[{ }^{\circ} \mathrm{C}\right]$} & {$\left[{ }^{\circ} \mathrm{C}\right]$} & temperature $[\%]$ \\
$5.5 \times 10^{4}$ & 3.4 & 67 & $1.1 \times 10^{6}$ & 2.3 & 1338 & 7 & 134 & 118 & 76 \\
\hline \hline
\end{tabular}

${ }^{\mathrm{a}}$ Low molecular weight.

${ }^{\mathrm{b}}$ High molecular weight.

ics simulations by Muthukumar and co-workers [17] describe a different scenario. Molecules with a high molar mass can retain a coiled conformation during flow. In fact, because of the presence of entanglements, the conformations of neighboring chains are related to each other and, ultimately, the stretch of a high-molar-mass chain can be blocked by surrounding unstretched chains. Furthermore, the hypothesis of a critical $M^{*}$ could suggest that shishes are formed only by high molecular weight chains. In contrast, Kornfield and co-workers highlighted the presence of low-molar-mass molecules within shishes. They used special polypropylene (PP) melts containing deutereted molecules [11]. These contradictory results point out the need for well-defined samples in FIC studies. Recent advances in catalyst science allow for a controlled "one pot" synthesis of linear high density polyethylene (HDPE) having a bimodal molecular weight distribution (MWD). The lowand the high-molar-mass (respectively, LMW and HMW) components of the MWD are generated at the same time from two different precatalysts immobilized on the same $\mathrm{MgCl}_{2}$ based support. A nascent blend of the $2 \mathrm{M}$ masses is produced with molecular scale mixing. More details on the synthesis are presented elsewhere [18]. These materials open new possibilities for FIC studies and, in this Letter, we describe, the conditions for generating a suspension of extended-chain (shish) crystals only out of a HDPE melt. The specifications of the bimodal HDPE investigated in this work are reported in Table I. The weight average molecular weight of HMW $\left(1.1 \times 10^{6} \mathrm{~g} / \mathrm{mol}\right)$ is $\sim 20$ times higher than that of LMW $\left(5.5 \times 10^{4} \mathrm{~g} / \mathrm{mol}\right)$ and the concentration of HMW chains (7 wt \%) is well above the critical overlap concentration $C^{*}=0.5 \mathrm{wt} \%$. For these reasons, a large influence of this Letter molecules on the FIC of these blends is expected. However, before drawing such a conclusion it is necessary to check some chain dynamics parameters. In this blend, entanglements between LMW and HMW molecules have a very limited lifetime. Constraint release (CR) could be so fast to lead to dynamic tube dilution (DTD) and, hence, to reduce the relaxation time of HMW molecules. DTD occurs when the Struglinski-Graessley number, $\mathrm{Gr}=Z_{\mathrm{HMW}} / Z_{\mathrm{LMW}}^{3}$, exceeds 0.06 [19]. $Z_{\mathrm{HMW}}$ and $Z_{\mathrm{LMW}}$ are the number of entanglements in HMW and LMW chains. For the investigated material $\mathrm{Gr} \cong 0.005$ and, therefore, DTD can be excluded. In this case, the disengagement time, $\tau_{D}$, and the retraction time, $\tau_{s}$, of a molecule can be calculated using the Doi-Edwards (DE) model [20]:

$$
\begin{gathered}
\tau_{D}=3 \tau_{e} Z^{3}(1-1.51 / \sqrt{Z})^{2} \\
\tau_{s}=\tau_{e} Z^{2}
\end{gathered}
$$

where $\tau_{e}$ is the equilibration time $\left(7 \times 10^{-9} \mathrm{~s}\right.$ at $\left.190^{\circ} \mathrm{C}\right)$. The values of $\tau_{D}$ and $\tau_{s}$, for HMW and LMW chains, at $142{ }^{\circ} \mathrm{C}$, are reported in Table II.

Structural and morphological developments after the application of a shear flow were characterized with x-ray scattering. WAXS was performed at the beam line ID11 of the European Synchrotron Radiation Facility (ESRF) (Grenoble, France) using a wavelength $\lambda=0.495 \AA$ and SAXS at the beam line BM26 of the ESRF using $\lambda=$ $1.24 \AA$. Shear flow was applied by means of a modified Linkam Shear Cell CSS-450. Crystallinity was calculated form WAXS data as the ratio between the intensity scattered by the crystals and the total scattered intensity.

According to classical thermodynamics [21], the driving force for nucleation is the reduction of the Gibbs free energy $(G): \Delta G<0$. In quiescent conditions, crystallization leads to FCC and the corresponding free energy change is $\Delta G_{q}=G_{\mathrm{FCC}}-G_{\mathrm{melt}}^{q}=\Delta H\left(1-T / T_{m}^{0}\right)$ where $\Delta H$ (negative value) is the latent heat and $T_{m}^{0}$ the equilibrium melting temperature for unconstrained crystals $\left(T_{m}^{0}=\right.$ $141.2^{\circ} \mathrm{C}$ ). Above $T_{m}^{0}$, FCC cannot be formed because of the lack of driving force $\left(\Delta G_{q}>0\right)$. However, nucleation is still possible when an extra driving is introduced, for instance, with flow. Flow increases the free energy of the melt $\left(G_{\text {melt }}^{f}>G_{\text {melt }}^{q}\right)$ promoting orientation and stretch of the molecules and tends to produce ECC that are more stable than FCC, i.e., have lower free energy $\left(G_{\mathrm{ECC}}<\right.$ $G_{\text {FCC }}$. Grizzuti and co-workers [22] accounted for the extra driving force due to flow, introducing an additive term $\left(\Delta G_{f}\right)$ in the free energy change: $\Delta G=\Delta G_{q}+$ $\Delta G_{f}$. With this definition, the equilibrium temperature rises to $T_{m}^{\text {flow }}=T_{m}^{0}\left(1+\Delta G_{f} / \Delta H\right)$ and crystallization be-

TABLE II. Relaxation times calculated with (1) and (2) at $142{ }^{\circ} \mathrm{C}$.

\begin{tabular}{lcc}
\hline \hline & $\tau_{D}[\mathrm{~s}]$ & $\tau_{s}[\mathrm{~s}]$ \\
\hline LMW & 0.01 & $9 \times 10^{-6}$ \\
HMW & 140 & 0.04 \\
\hline \hline
\end{tabular}




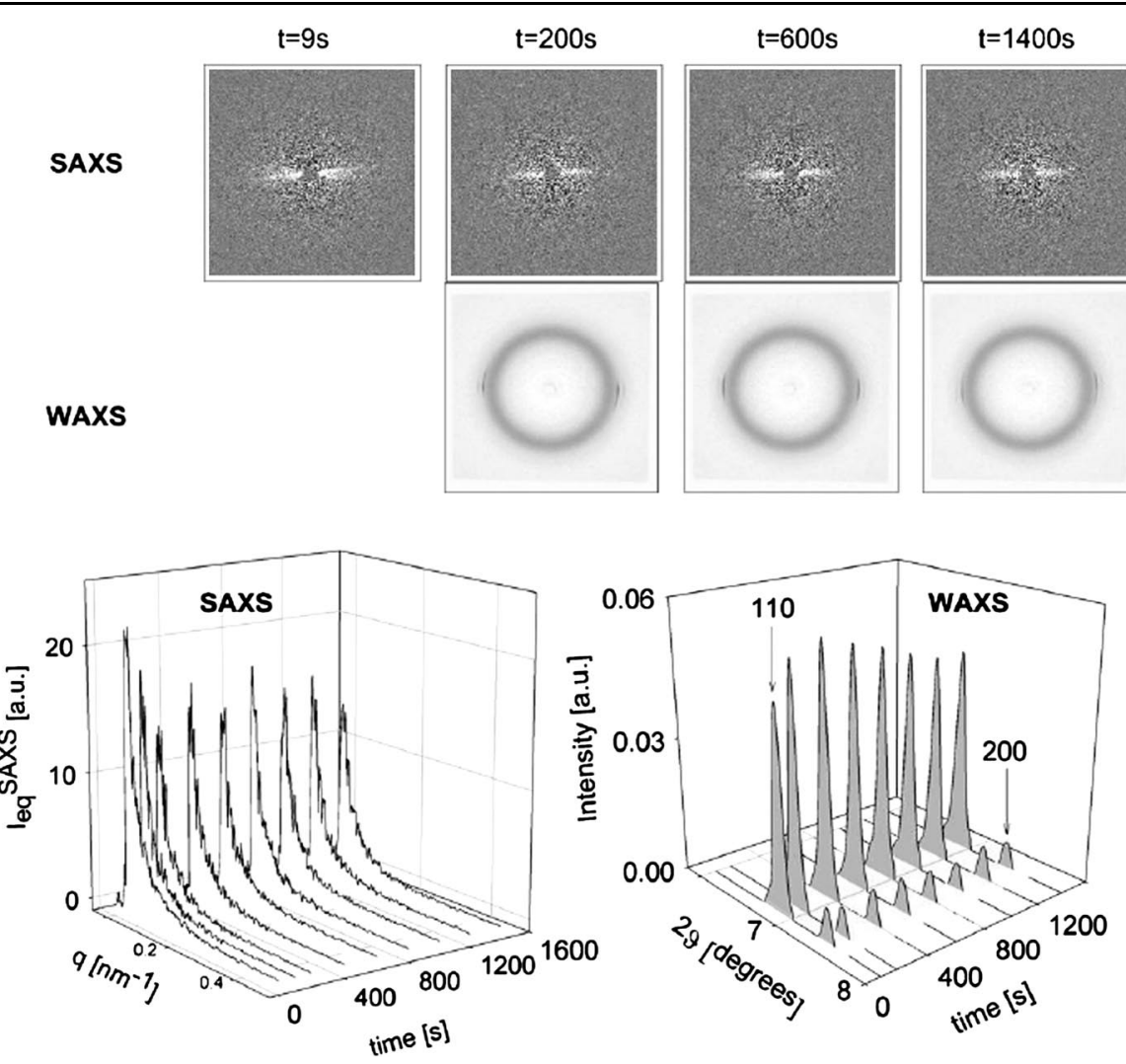

FIG. 2. SAXS and WAXD data recorded after the application of a shear of $120 \mathrm{~s}^{-1}$ for $1 \mathrm{~s}$ at $142^{\circ} \mathrm{C}$. In the two-dimensional scattering images shown at the top, the flow direction is vertical. For the WAXD intensity, the scattering of the amorphous component was subtracted and only the crystalline peaks are visible.

comes possible even above $T_{m}^{0}$. In these conditions, where FCC cannot be formed and flow is the only driving force, only ECC can be formed when the driving force is large enough, i.e., when there is a sufficient degree of chain orientation and stretch. The capability of the flow of inducing orientation and stretch of the chains can be quantified defining two Deborah numbers [23]: $\mathrm{De}_{\mathrm{or}}=\tau_{D} \dot{\gamma}$ and $\mathrm{De}_{\mathrm{str}}=\tau_{s} \dot{\gamma}$ that measure the ratio between flow and relaxation rates at chain and segmental level, respectively. Chain orientation is achieved when $\mathrm{De}_{\text {or }}$ exceeds unity while chain stretch when $\mathrm{De}_{\text {str }}$ exceeds unity. After cessation of flow a chain is confined in a virtual tube that limits its conformations. The random coil conformation can be attained again only by reptation of the chain out of the tube. The fraction $\mu$ of the chain that is included in the tube decreases with time according to fading memory function:

$$
\mu\left(t ; \tau_{D}\right)=\frac{8}{\pi^{2}} \sum_{p \text { odd }} \frac{1}{p^{2}} \exp \left(-p^{2} \frac{t-t_{0}}{\tau_{D}}\right) .
$$

Figure 2 shows $\mathrm{x}$-ray scattering data after application of shear with $\dot{\gamma}=120 \mathrm{~s}^{-1}$ for $1 \mathrm{~s}$ at $142^{\circ} \mathrm{C}$. This flow is efficient in orienting and stretching HMW chains as $\mathrm{De}_{\text {or }}^{\mathrm{HMW}}=1.6 \times 10^{4}$ and $\mathrm{De}_{\mathrm{str}}^{\mathrm{HMW}}=4.5$, while it can hardly orient and surely not stretch LMW chains as $\mathrm{De}_{\mathrm{or}}^{\mathrm{LMW}}=1.5$ and $\mathrm{De}_{\text {str }}^{\mathrm{LMW}}=0.01$. Immediately after flow $(t=0 \mathrm{~s})$, SAXS images show an equatorial streak indicating the formation of needlelike precursors aligned in the shear direction. This scattering pattern is retained for the whole experimental time (1600 s). Simultaneously, wide angle $\mathrm{x}$-ray diffraction (WAXD) images show the fingerprint of an orthorhombic lattice (with 110 and 200 reflections) having a high degree of orientation. Interestingly, the integrated intensity of the SAXS equatorial streak, $I_{\mathrm{eq}}^{\mathrm{SAXS}}$, and the calculated WAXD crystallinity, $X^{\mathrm{WAXD}}$ do not follow the same trend during the initial transient of $\sim 160 \mathrm{~s}^{-1}$. As shown in Fig. 3, $I_{\mathrm{eq}}^{\mathrm{SAXS}}$ builds

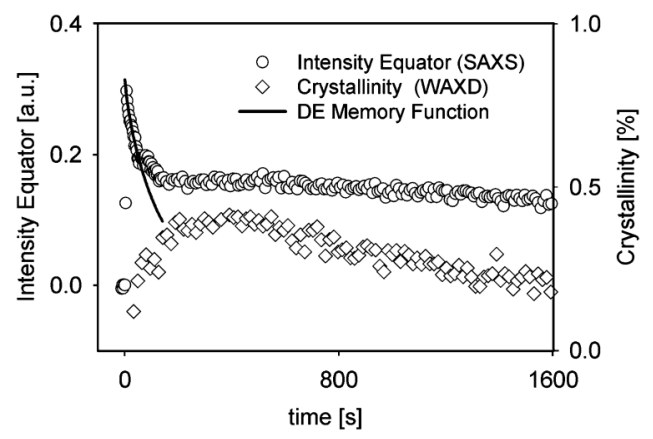

FIG. 3. $I_{\mathrm{eq}}^{\mathrm{SAXS}}$ and $X^{\mathrm{WAXD}}$ as a function of time after step shear at $142{ }^{\circ} \mathrm{C}$. The initial drop of $I_{\text {eq }}^{\text {SAXS }}$ can be fitted with the memory function of the Doi-Edwards (DE) model, the fit is represented by the continuous line. 

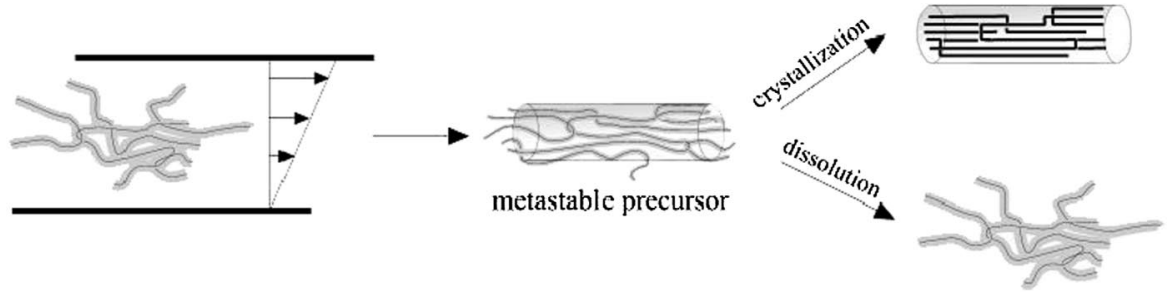

FIG. 4. Crystallization or dissolution of flow-induced precursors depends on their size. The thick gray line represents the tube containing the chain.

up quickly reaching a maximum at $t_{\max }=6 \mathrm{~s}$ and then decreases exponentially while $X^{\mathrm{WAXD}}$ builds up gradually to the stationary value of $0.4 \%$. This experimental evidence suggests the formation of a polydisperse set of needlelike precursors that, initially, are characterized by very limited or no crystallinity. The stability of precursors is related to their size. Those exceeding some critical size are stable and have time to refine their structure to a proper crystal lattice forming shishes, thus increasing the crystallinity. Those that are smaller than the critical size dissolve back into the melt state, decreasing $I_{\mathrm{eq}}^{\mathrm{SAXS}}$. In the first $60 \mathrm{~s}$, as shown in Fig. 3, the drop of $I_{\mathrm{eq}}^{\mathrm{SAXS}}$ is well described with the DoiEdwards memory function with a vertical shift factor $S_{y}$ :

$$
I_{\mathrm{eq}}^{\mathrm{SAXS}}(t)=S_{y} \sum_{p \text { odd }} \frac{1}{p^{2}} \exp \left(-p^{2} \frac{t-t_{\mathrm{max}}}{\tau_{D}^{\mathrm{HMW}}}\right)
$$

where $\tau_{D}^{\mathrm{HMW}}=140 \mathrm{~s}$, obtained from (1), is the only time constant. $S_{y}$ is used as fit parameter. The good correlation between data points strongly suggests that dissolution of the precursors involves reptation of HMW chains and, ultimately, that stretched HMW chains are the precursor's backbones. For times longer than $60 \mathrm{~s}$, dissolution of precursors slows down dramatically and at $\sim 200$ s a steady state is approached: both $I_{\mathrm{eq}}^{\mathrm{SAXS}}$ and $X^{\mathrm{WAXD}}$ remain constant indicating the presence of stable and crystalline shishes. The Bragg spacings corresponding to the 110 and 200 crystalline peaks are $d_{110}=4.14 \AA$ and $d_{200}=$ $3.86 \AA$ and they are independent of time. Therefore, the unit cell parameters $a=2 d_{200}=7.6 \AA$ and $b=$ $\left[\left(d_{110}\right)^{-2}-\left(2 d_{200}\right)^{-2}\right]^{-1 / 2}=4.9 \AA$ are also independent of time. The (apparent) lateral size of the shishes in the 110 and 200 directions (calculated with Scherrer's equation) is $D_{110}=210 \AA$ and $D_{200}=310 \AA$. At this high temperature, the stability of such a suspension of shishes is limited to $\sim 400 \mathrm{~s}$. When $t \approx 600 \mathrm{~s}$, both $I_{\mathrm{eq}}^{\mathrm{SAXS}}$ and $X^{\mathrm{WAXD}}$ start to slowly decrease indicating that the shishes slowly melt.

In conclusion, we show that by applying shear flow to a bimodal HDPE melt it is possible to generate a suspension of only extended-chain shishes. This is feasible at high temperatures, just above the equilibrium melting temperature of folded chain lamellae. As depicted in Fig. 4, the $\mathrm{x}$-ray data support a pathway for shish formation based on the stretch of the HMW molecules and passing through metastable needlelike precursors. These precursors can crystallize forming shishes or dissolve via a mechanism based on the reptation of their HMW backbone.

The authors wish to thank G. Portale (BM26, ESRF) and C. Curfs (ID11, ESRF) for support during the X-ray experiments. This work is a part of the Research Programme of the Dutch Polymer Institute [24], Projects No. 132 and No. 321.

*Corresponding author. s.rastogi@tue.nl

[1] F. L. Binsbergen, Nature (London) 211, 516 (1966).

[2] J. Pennings and A. M. Kiel, Kolloid Z. 205, 160 (1965).

[3] M. Seki et al., Macromolecules 35, 2583 (2002).

[4] G. Kumaraswamy et al., Macromolecules 35, 1762 (2002).

[5] S. Yamazaki et al., Polymer 46, 1685 (2005).

[6] J.K. Hobbs, A.D.L. Humphris, and M. J. Miles, Macromolecules 34, 5508 (2001).

[7] I. Lieberwirth et al., J. Polym. Sci. B 38, 1183 (2000).

[8] M. Garcia Gutierrez et al., Macromolecules 37, 478 (2004).

[9] E. L. Heeley et al., Macromolecules 39, 5058 (2006).

[10] Y. Ogino et al., Polymer 47, 5669 (2006).

[11] S. Kimata et al., Science 316, 1014 (2007).

[12] R. H. M. Swartjes et al., Int. Polymer Processing 18, 53 (2003).

[13] J. Baert and P. Van Puyvelde, Polymer 47, 5871 (2006).

[14] H. Janeschitz-Kriegl and G. Eder, J. Macromol. Sci., Phys. 46, 591 (2007).

[15] B. S. Hsiao et al., Phys. Rev. Lett. 94, 117802 (2005).

[16] A. Keller and H. W. H. Kolnaar, Flow Induced Orientation and Structure Formation (VCH, New York, 1997), Vol. 18.

[17] I. Dukovski and M. Muthukumar, J. Chem. Phys. 118, 6648 (2003).

[18] N. Kukalyekar, S. Rastogi, and J.C. Chadwick, Polym. Prepr. 48, 280 (2007).

[19] J. M. Dealy and R. G. Larson, Structure and Rheology of Molten Polymers (Hanser Gardner Publications, Cincinnati, OH, 2006).

[20] M. Doi and S.F. Edwards, The Theory of Polymer Dynamics (Clarendon Press, Oxford, U.K., 1986).

[21] M. Muthukumar, Adv. Chem. Phys. 128, 1 (2004).

[22] S. Coppola et al., Polymer 45, 3249 (2004).

[23] J. van Meerveld, G. W. M. Peters, and M. Hutters, Rheol. Acta 44, 119 (2004).

[24] Dutch Polymer Institute (DPI), P.O. Box 902, 5600 AX Eindhoven, The Netherlands. 